\title{
Biogenic Amines and Aflatoxins in Some Imported Meat Products: Incidence, Occurrence, and Public Health Impacts
}

\author{
Fahad Dhafer Algahtani, ${ }^{1}$ Alaa Eldin Morshdy, ${ }^{2}$ Mohamed A. Hussein, ${ }^{2}$ \\ Essam Said Abouelkheir, ${ }^{2}$ Adeniyi Adeboye, ${ }^{1}$ Andrea Valentine, ${ }^{3}$ \\ and Mohamed Tharwat Elabbasy $\mathbb{D}^{1,2}$ \\ ${ }^{1}$ Public Health Department, College of Public Health and Health Informatics, Ha'il University, Ha'il, Saudi Arabia \\ ${ }^{2}$ Food Control Department, Faculty of Veterinary Medicine, Zagazig University, Zagazig, Egypt \\ ${ }^{3} U K C B C /$ Bath Spa University Programme, London, UK \\ Correspondence should be addressed to Mohamed Tharwat Elabbasy; tharwat330@gmail.com
}

Received 28 November 2019; Revised 23 February 2020; Accepted 14 March 2020; Published 29 July 2020

Academic Editor: Luca Campone

Copyright (C) 2020 Fahad Dhafer Algahtani et al. This is an open access article distributed under the Creative Commons Attribution License, which permits unrestricted use, distribution, and reproduction in any medium, provided the original work is properly cited.

\begin{abstract}
Background. Since the beginning of humanity, the global burden of foodborne disease has had a decimating effect on populations, with biogenic amines (BAs) and aflatoxins in meat products implicated. While many developed countries have legitimized safety levels for BAs using evidence-based guidelines to attain high food quality standards for consumers of meat products, developing countries are still battling against poor food quality checking. Purpose. This study examines the level of health risk of biogenic amines and aflatoxin in meat products by extracting and estimating their residues and determining their indices as a way of monitoring the potential health impacts of these residues on consumers of meat products. Methods. A total of 40 imported meat products sampled and randomly collected, representing imported luncheon meat, hot dog sausages, corned beef, and minced meat. Using recommended laboratory protocols, eight residues of BAs and aflatoxins were extracted. Results. Eight BAs, histamine, tyramine, tryptamine, cadaverine, putrescine, $\beta$-phenyl ethylamine, spermine, and spermidine, were extracted and determined in all tested samples. Tyramine levels in luncheon meat were found to be significantly higher than in other meat products, while significantly high cadaverine levels were reported in corned beef samples. The results of biogenic amine index (BAI) revealed that the quality of imported minced meat and imported hot dog samples was good (BAI $<5 \mathrm{mg} / \mathrm{kg})$, while imported luncheon meat and imported corned beef samples remained acceptable (BAI 5-20 mg/kg). Aflatoxin B1 (AFB1) was detected higher than the permissible limit $(>5 \mu \mathrm{g} / \mathrm{kg})$ in imported luncheon meat and imported hot dog meat samples. Conclusion. The general results indicate that testing meat products for biogenic amines and aflatoxins is a very good indicator for monitoring the freshness and quality of meat products.
\end{abstract}

\section{Introduction}

Meat products are viewed as probably the food items which draw in the most customers for their palatability, high biological and nutritive value, low price, and easy preparation compared to fresh meat [1].

These days, food safety is of significant concern in public health. Although developed countries have built up legitimate rules, guidelines, and quality models for monitoring food quality, developing countries are still battling with poor food quality checking [2]. Recent trends in food hygiene focus on aggravates that can affect consumers' health, such as biogenic amines (BAs) [3].

BAs are formed by the removal of the $\alpha$-carboxyl group from amino acids and they are usually named after the corresponding precursor amino acid; for example, histidine is decarboxylated to produce histamine, tryptophan to tryptamine, tyrosine to tyramine, and lysine to cadaverine. However, putrescine can be created from three amino acids: glutamine, arginine, and agmatine [4-7]. 
BAs have been reported as present in various foods where they have been linked to health damage. Two wellknown BA poisonings are "scombroid poisoning" from the consumption of fish from the Scombridae family which contains histamine and "cheese reaction" from cheese consumption related to tyramine. The first reported case of BA poisoning occurred in 1967 in the Netherlands and involved Gouda cheese [8-10]. The essential significance of BAs is that the utilization of foods containing a high concentration may cause food intoxication with manifestations including flushes, cerebral pains, sickness, cardiovascular palpitations, and expanded or diminished circulatory strain $[11,12]$. The generation of BAs has been related to yeast and Gram-negative and Gram-positive microbes [13-16].

Histamine is the BA most commonly connected with the beginning of outbreaks [8]. Any foodstuffs delivered by fermentation or exposed to microbial tainting may implicate BAs, so monitoring of BA levels in meat products is of great interest [3].

Mycotoxins are harmful substances delivered by organisms of Aspergillus, Penicillium, and Fusarium fungal genera that debase food and are responsible for some serious illness [2].

The most significant food mycotoxins are aflatoxin, ochratoxin, fumonisins, moniliformin, and zearalenone. The noteworthy danger to wellbeing presented in the utilization of mycotoxin-contaminated food products is of extreme concern to many developing countries [17].

This study used a risk analysis approach for monitoring BAs and aflatoxin residues in some imported meat products, focusing specifically on the risk assessment, management, and public health impact of these residues.

\section{Materials and Methods}

2.1. Test Protocol. A total of 40 imported meat products samples were randomly collected and represented by imported luncheon meat, imported hot dog meat, imported corned beef, and imported minced meat. Ten of each were randomly collected from different supermarkets from different regions of Zagazig, Egypt. Each sample was separately packed in a sterile plastic bag and immediately transferred to the laboratory in an ice box.

2.2. Determination of Biogenic Amines in Meat Products Using High Performance Liquid Chromatography (HPLC). Eight BAs, histamine, tyramine, tryptamine, cadaverine, putrescine, $\beta$-phenyl ethylamine, spermine, and spermidine, were extracted and determined in all tested samples as described by MIETZ [18].

2.2.1. Reagents Preparation. Biogenic amines standards (cadaverine, histamine, tyramine, spermidine, and spermine), dansyl chloride (Dns-Cl), acetonitrile, and acetone for HPLC were from Sigma Chemical Co.; the other reagents used in this study were HPLC-grade. For dansyl chloride solution, $500 \mathrm{mg}$ of dansyl chloride was dissolved in $100 \mathrm{ml}$ of acetone. For standard solutions, stock standard solutions of the tested amines were prepared as follows: add $25 \mathrm{mg}$ of each standard pure amine (histamine- $2 \mathrm{HCl}$, tyramine- $2 \mathrm{HCl}$, cadaverine- $2 \mathrm{HCl}$, putrescine- $2 \mathrm{HCl}$, tryptamine- $2 \mathrm{HCl}$, spermidine-2HC1 spermine- $2 \mathrm{HCL}$, and $\beta$-phenyl ethylamine) were dissolved in $25 \mathrm{ml}$ of distilled water individually.

2.2.2. Extraction of Samples. Twenty-five grams of homogenised samples was blended with $125 \mathrm{ml}$ of $5 \%$ trichloroacetic acid (TCA) for 3 minutes and then filtration was achieved using Whatman (1) filter paper. Ten milliliters of the extracts (filtrate) were transferred into a suitable glass tube with $4 \mathrm{~g}$ of $\mathrm{NaCl}$ and $1 \mathrm{ml}$ of $50 \% \mathrm{NaOH}$ and were shaken well. The filtrate was extracted three times ( 2 minutes each) by utilising $5 \mathrm{ml}$ of $\mathrm{n}$-butanol: chloroform $(1: 1 \mathrm{v} / \mathrm{v})$ and the upper clear layer was moved to a $100 \mathrm{ml}$ isolating funnel. To combine the organic extracts (upper layer), $15 \mathrm{ml}$ of $\mathrm{n}$-heptane was added in a separating funnel and extracted three times with $1.0 \mathrm{ml}$ portions of $0.2 \mathrm{NHCl}$; the $\mathrm{HCl}$ layer was gathered in a glass stoppered cylinder. A water bath at $95^{\circ} \mathrm{C}$ was used to evaporate the solution.

2.2.3. Formation of Dansyl Amines. One hundred microliters of each stock standard solution (or sample extract) was transferred to $50 \mathrm{ml}$ vials and dried under vacuum. About $0.5 \mathrm{ml}$ of soaked $\mathrm{NaHCO} 3$ was added and mixed and then $1.0 \mathrm{ml}$ of dansyl chloride solution was added and mixed thoroughly using a vortex mixer. The mixture was incubated at $55^{\circ} \mathrm{C}$ for 45 minutes and then $10 \mathrm{ml}$ of distilled water was added and the mixture was shaken using a vortex mixer. The extraction of dansylated BAs was carried out using $5 \mathrm{ml}$ of diethyl ether three times with vigorous shaking for 11 minutes. After collection, the combined ether extracts were carefully evaporated at $35^{\circ} \mathrm{C}$ in a dry bath with the aid of current air. The dry material obtained was broken down in $1 \mathrm{ml}$ of methanol and then 10 microliters was injected using Agilent 1100 HPLC system, C18 column, $7 \mu \mathrm{m}$, and $4.6 \mathrm{~cm} \times 150 \mathrm{~mm}$ (Merck, Darmstadt, Germany), with diode-array detector (set at $254 \mathrm{~nm})(\mathrm{S} 1)$.

2.2.4. Biogenic Amine Index (Bai). Biogenic amine index (BAI) was determined by summing up tyramine, histamine, putrescine, and cadaverine levels in the distinctive meat types: good quality $(\mathrm{BAI}<5 \mathrm{mg} / \mathrm{kg}$, acceptable (BAI $5-20 \mathrm{mg} / \mathrm{kg}$ ), poor quality (BAI $20-50 \mathrm{mg} / \mathrm{kg}$ ), and spoiled $(\mathrm{BAI}>50 \mathrm{mg} / \mathrm{kg})[19]$.

2.3. Quantitative Estimation of Aflatoxin Residues (B1, B2, G1, and G2) in Meat Products Using HPLC as Described by Herzallah [20]

2.3.1. Aflatoxins Working Standards. Aflatoxins standards (B1, B2, G1, and G2) were purchased from Sigma (St. Louis, MO, USA). The stock standard solution was prepared from a vial of aflatoxins mixture standard powder containing $5 \mathrm{mg}$ (2 mg $\mathrm{AFB}_{1}, 2 \mathrm{mg} \mathrm{AFG}_{1}, 0.5 \mathrm{mg} \mathrm{AFB} 2$, and $0.5 \mathrm{mg} \mathrm{AFG}$ ) by 
dissolving powder in $10 \mathrm{ml}$ of acetonitrile to make a stock solution of $500 \mathrm{ppm}$ concentration (Figures 1 and S2).

2.3.2. Aflatoxins Extraction. One hundred grams of the sample was homogenised and blended well with $10 \mathrm{ml}$ of $20 \%$ citric acid created by including $200 \mathrm{ml}$ of dichloromethane and the blend was kept in a programmed shaker for 30 minutes. The blend was separated and the filtrated materials were evaporated under vacuum. Finally, hexane was added to the extracted material.

2.3.3. Clean-Up. Clean-up was performed using solid-phase extraction (SPE) columns, Bond Elut C18 $(500 \mathrm{mg}, 3 \mathrm{ml}$ or $6 \mathrm{ml}$; Varian, Les Ulis, France). The extracted materials were poured onto the top of the gel in the column and eluted with hexane to remove fats. Other impurities were removed by a mixture of hexane, ether, and acetonitrile in the ratio of $1: 3$ : 6 . The column was eluted with a mixture of dichloromethane and acetone (elution solution) to recover or obtain aflatoxins. The organic solvent was evaporated using nitrogen evaporator (Turbo Vap ${ }^{\circledR}$ LV, Caliper) to dryness.

2.3.4. HPLC Determination. Twenty microliters of the solution was injected into HPLC including an isocratic mobile phase consisting of deionized water: acetonitrile: methanol $(60: 20: 20 \mathrm{v} / \mathrm{v} / \mathrm{v})$ using a gradient method with a flow rate of $1 \mathrm{ml} / \mathrm{min}$ at a temperature of $30^{\circ} \mathrm{C}$. The separation was carried out on a reversed-phase column (Extend-C18, Zorbax column, $4.6 \mathrm{~mm} \times 250 \mathrm{~mm}, 5 \mu \mathrm{m}$, Agilent Co.). The detection was done by a fluorescence detector set at wave length $360 \mathrm{~nm}$ excitation and $440 \mathrm{~nm}$ emission. Quantification of residues in samples was obtained and calculated from an area under the curves extrapolated by automatic ChemStation software. A calibration curve was prepared by using a concentration of $275,550,1375,2750$, and $4450 \mathrm{ppb}$ of aflatoxin mixture standards in eluent.

2.4. Statistical Analysis. Data were analyzed using the Pearson correlation test and one-way ANOVA significant at $P<0.05$ [21].

\section{Result and Discussion}

BAs in products are noteworthy for their toxicological effects and because of their interaction with certain medications and they have been utilized as quality indicators in certain foods $[7,22]$.

The data presented in Figure 2 shows that histamine was detected in all examined samples with mean values of $1.41 \pm 0.09,0.63 \pm 0.46,1.18 \pm 0.26$, and $1.14 \pm 0.95 \mathrm{mg} / \mathrm{kg}$ in examined luncheon meat, hot dog meat, corned beef, and minced meat, respectively. In literature, there are nearly comparable outcomes for histamine levels in meat products [23]. The luncheon meat samples showed significantly lower levels of histamine than the other examined products, which did not show significant variations between them. The selection of raw material for the manufacture of luncheon

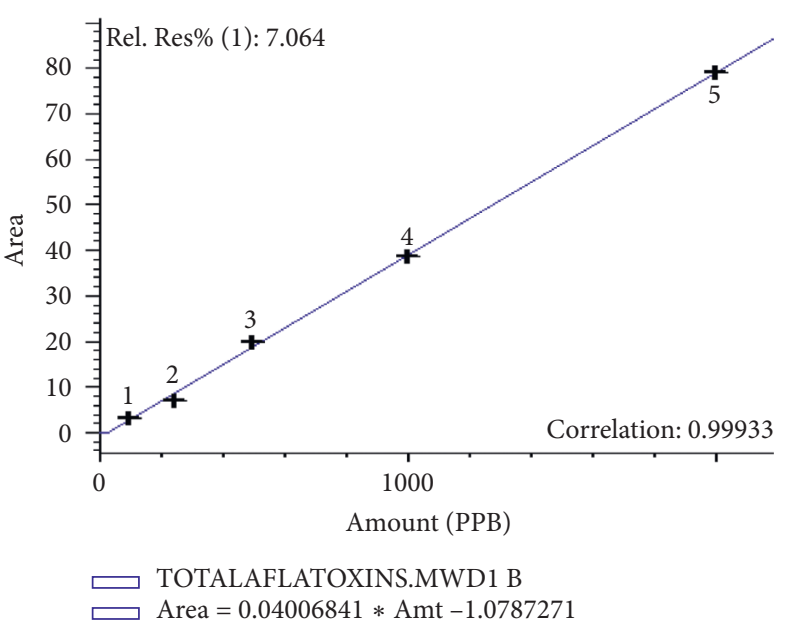

Figure 1: Calibration curve of total aflatoxin in ppb using five concentrations.

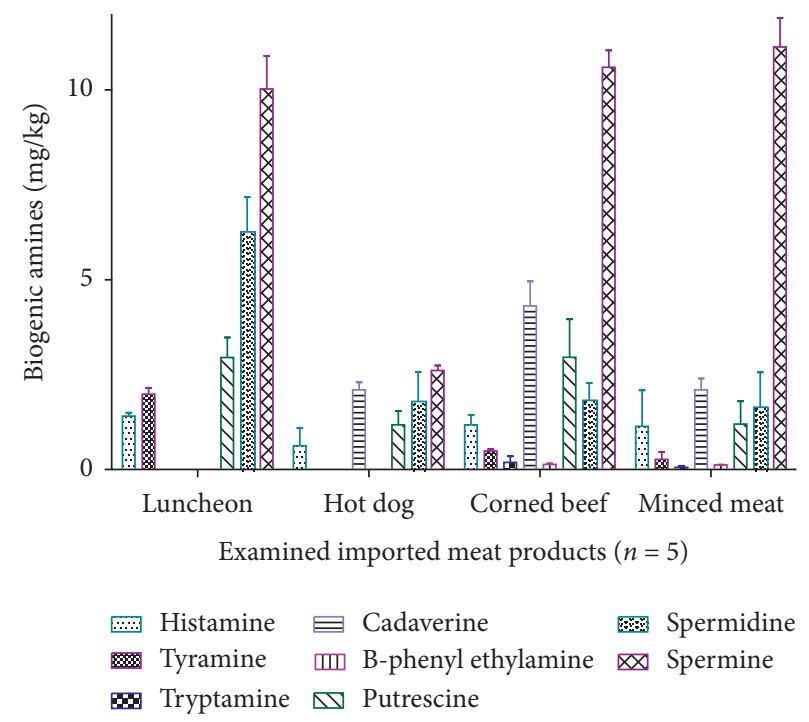

Figure 2: Biogenic amine levels $(\mathrm{mg} / \mathrm{kg}$ ) in examined imported meat products $(n=5)$.

meat may affect histamine content in the final products. Moreover, processing temperature had an influence on the release of histamine [24]. The most common symptoms of histamine poisoning are due to the effect on the cardiovascular system, producing low blood pressure, reddening of the skin, headaches, edema, and rashes typical of allergic reactions [25]. The variations between histamine levels in meat products are due to different methods of food processing, which plays an important role in controlling the formation of BAs in meat products. Histamine is one chemical indicator of spoilage. The amount of histamine formed depends on the type of the product, the microbial load, temperature, handling, and storage conditions.

It is evident from the results reported in Figure 2 that the mean values of tyramine levels for the examined imported luncheon meat, imported corned beef, and imported minced meat were $1.985 \pm 0.16,0.49 \pm 0.05$, and $0.27 \pm 0.19 \mathrm{mg} / \mathrm{kg}$, respectively. Tyramine levels in luncheon meat had a 
significantly higher level than other meat products. In literature, tyramine levels were detected and were 13.25 to $14.91 \mathrm{mg} / \mathrm{kg}$ [23], $6.75 \mathrm{mg} / \mathrm{kg}$ [26], $29.81 \mathrm{mg} / 100 \mathrm{~g}$ [27], and $7.24 \mathrm{mg} / \mathrm{kg}$ [28]. It is apparent from the outcomes reported in Figure 2 that the tryptamine was found in imported corned beef and imported minced meat samples only, with mean values of $0.19 \pm 0.16$ and $0.06 \pm 0.04 \mathrm{mg} / \mathrm{kg}$, respectively.

The obtained results in Figure 2 revealed that cadaverine was not detected in the examined imported luncheon meat. The mean values of cadaverine levels for hot dog meat, corned beef, and minced meat were $2.1 \pm 0.2,4.31 \pm 0.65$, and $2.1 \pm 0.3 \mathrm{mg} / \mathrm{kg}$, respectively $[23,29]$. Significantly high cadaverine levels were reported in corned beef samples. Putrescine and cadaverine, despite the fact that they are not viewed as lethal separately, can increase the impact of histamine and tyramine by interfacing with the amino oxidases and meddling with the detoxifying system [30, 31].

Beta-phenyl-ethylamine (PHE) was detected in imported corned beef and imported minced meat with mean values of $0.136 \pm 0.025$ and $0.125 \pm 0.007 \mathrm{mg} / \mathrm{kg}$, respectively (Figure 2). Putrescine was detected in all examined samples with a mean values of $2.95 \pm 0.53,1.18 \pm 0.36,2.96 \pm 1.00$, and $1.2 \pm 0.6 \mathrm{mg} / \mathrm{kg}$ for luncheon meat, hot dog meat, corned beef, and minced meat, respectively [29, 32]. Putrescine development in meat is for the most part ascribed to the microbial decarboxylation of ornithine and may likewise be delivered from the decarboxylation of arginine and consequent deamination of the transitionally created agmatine [33].

Polyamines, such as spermidine and spermine, do not exert a direct toxic effect. However, they inhibit histamine or tyramine detoxifying enzymes and thus act as enhancers of their toxicity. These amines in the intestinal tract compete for the detoxifying enzymes that tend to increase the level of histamine and tyramine in blood [34].

Spermidine was detected in all examined samples, with mean values of $6.26 \pm 0.92,1.79 \pm 0.78,1.82 \pm 0.46$, and $1.64 \pm 0.92 \mathrm{mg} / \mathrm{kg}$ in examined luncheon meat, hot dog meat, corned beef, and minced meat, respectively. Nearly similar levels of spermidine were detected in dry-cured lacón (a Spanish traditional meat product) with a range of 6.88 to $7.22 \mathrm{mg} / \mathrm{kg}$ [35]. Spermine was detected in all examined samples with mean values of $10.03 \pm 0.87,2.61 \pm 0.13$, $10.6 \pm 0.44$, and $11.13 \pm 0.77 \mathrm{mg} / \mathrm{kg}$ in examined luncheon meat, hot dog meat, corned beef, and minced meat, respectively. Higher level of spermine was detected in drycured lacón with a range of 22 to $27 \mathrm{mg} / \mathrm{kg}$ [35].

Regarding the biogenic amine index (BAI), Figure 3, the quality of imported minced meat and imported hot dog samples was good, while imported luncheon meat and imported corned beef samples remained acceptable through the examination. This BAI seems to be more suitable as a quality index for the freshness of meat products [25].

Aflatoxin B1 (AFB1) is the most lethal mycotoxin to animals and humans and was classified as a Group 1 human carcinogen [36]. Aflatoxin B1 residue levels ranged from 2.4 to 12.06 with a mean value of $7.23 \pm 0.8 \mu \mathrm{g} / \mathrm{kg} ; 1.8$ to 13 with a mean value of $5.63 \pm 0.95 \mu \mathrm{g} / \mathrm{kg}$; ND to 8.31 with a mean

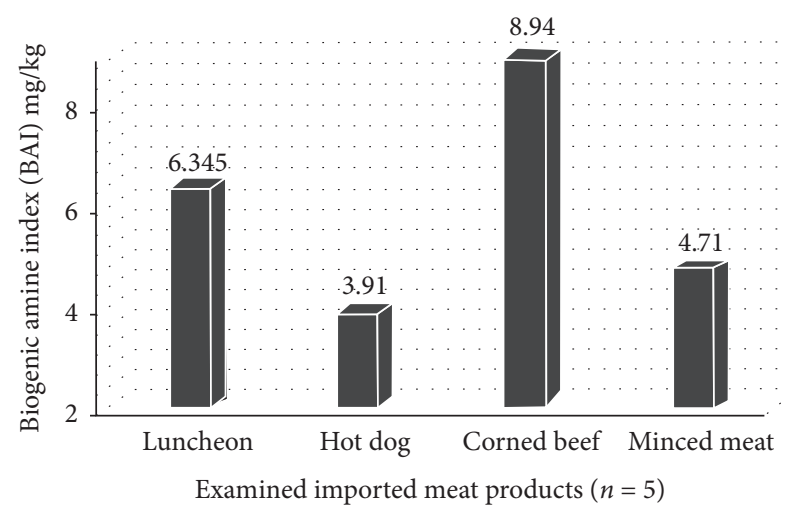

FIgURE 3: Biogenic amines index (BAI) $(\mathrm{mg} / \mathrm{kg})$ in examined imported meat products, good quality $(\mathrm{BAI}<5 \mathrm{mg} / \mathrm{kg}$, acceptable (BAI $5-20 \mathrm{mg} / \mathrm{kg}$ ), poor quality (BAI $20-50 \mathrm{mg} / \mathrm{kg}$ ), and spoiled (BAI > $50 \mathrm{mg} / \mathrm{kg}$ ).

value of $4.88 \pm 0.11 \mu \mathrm{g} / \mathrm{kg}$; and ND to 2.8 with a mean value of $2.03 \pm 0.3 \mu \mathrm{g} / \mathrm{kg}$ in examined imported luncheon meat, imported hot dog meat, imported corned beef, and imported minced meat, respectively (Figure 4 ). There were significant differences between examined samples $(P<0.05)$. The highest level of aflatoxin B1 was detected in luncheon meat and the lowest level was detected in minced meat, which may be due to the use of meat additives previously contaminated with aflatoxins. A similar finding was obtained by Ismail et al. [37]. The mean values of detected AFB1 in the examined imported luncheon meat and imported hot dog meat were higher than the permissible limit recommended by the WHO and the European Union, which set $5 \mu \mathrm{g} / \mathrm{kg}$ as a maximum level for AFB1 [38].

Food consumption contaminated with aflatoxin, even in small amounts, leads to the accumulation of this toxin in the liver, causing a carcinogenic effect. Even very low concentration levels ( $1 \mathrm{ppb}$ ) would lead to a major public health hazard, as consuming $28 \mathrm{mg}$ of AFB1 over a lifetime can cause cancer [39].

Aflatoxin G1 residue levels ranged from ND to 6.94 with a mean value of $4.37 \pm 0.63 \mu \mathrm{g} / \mathrm{kg}$; ND to 5.64 with a mean value of $5.63 \pm 0.2 \mu \mathrm{g} / \mathrm{kg}$; ND to 5.8 with a mean value of $6.9 \pm 0.63 \mu \mathrm{g} / \mathrm{kg}$; and ND to 5.35 with a mean value of $5.53 \pm 0.1 \mu \mathrm{g} / \mathrm{kg}$ in examined luncheon meat, hot dog meat, corned beef, and minced meat samples, respectively (Figure 4). There were significant differences between examined samples $(P<0.05)$. The highest level of aflatoxin $\mathrm{G} 1$ was detected in corned beef and lowest level was detected in minced meat, which may be due to the use of meat additives previously contaminated with aflatoxins. Aflatoxin B2 residues were detected only in imported hot dog meat samples and their levels ranged from ND to 4.5 with a mean value of $3.17 \pm 0.4 \mu \mathrm{g} / \mathrm{kg}$ (Figure 4). Aflatoxin G2 residue levels ranged from ND to 5.23 with a mean value of $4.61 \pm 0.66 \mu \mathrm{g} /$ $\mathrm{kg}$ and ND to 6.1 with a mean value of $3.89 \pm 0.38 \mu \mathrm{g} / \mathrm{kg}$, in examined imported corned beef and imported minced meat, respectively (Figure 4).

It is obvious from the outcomes exhibited in Figure 5 that the total aflatoxin residues $\left(B_{1}+B_{2}+G_{1}+G_{2}\right)$ were detected 


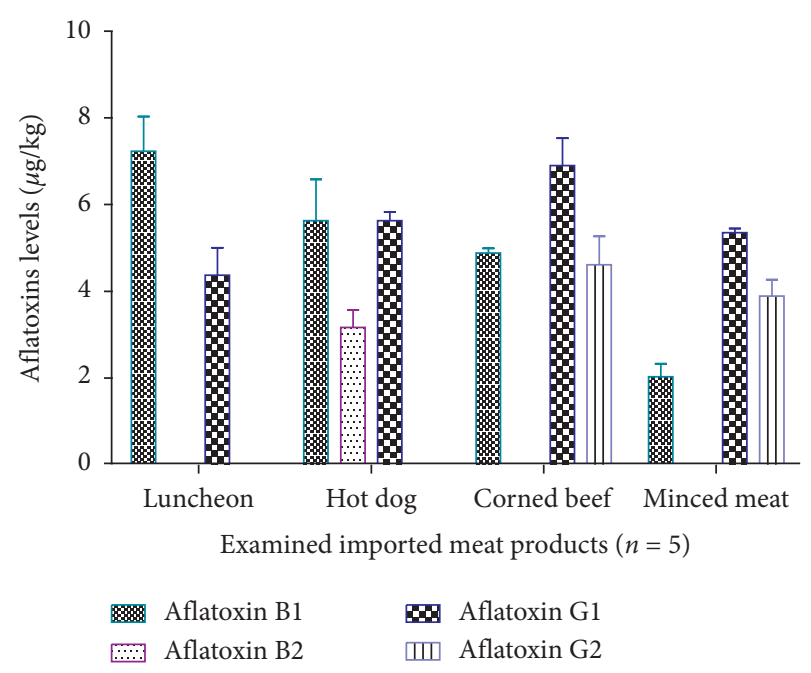

Figure 4: Aflatoxin B1, B2, G1, and G2 levels $(\mu \mathrm{g} / \mathrm{kg})$ in the examined imported meat products.

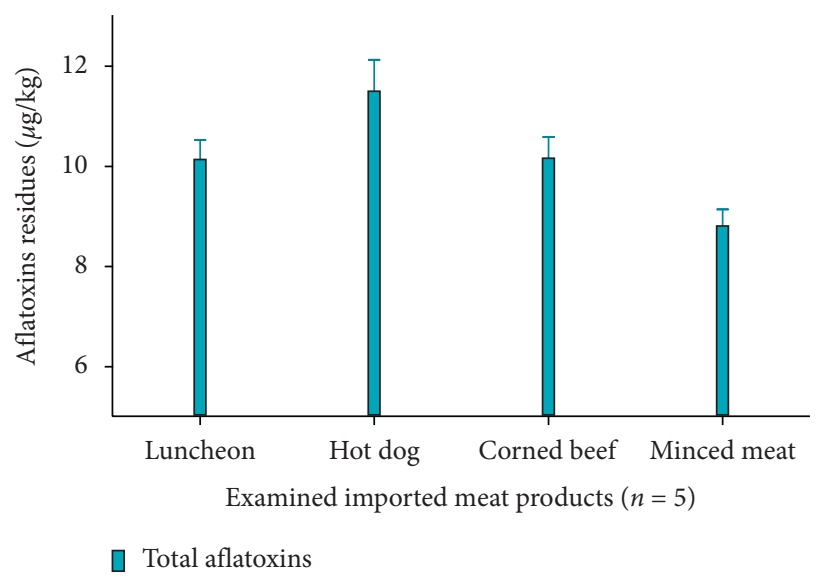

Figure 5: Average of total aflatoxin residues $(\mu \mathrm{g} / \mathrm{kg})$ in examined imported meat products.

in the examined imported luncheon meat, imported hot dog meat, imported corned beef, and imported minced meat samples with mean values of $10.14 \pm 0.39 \mu \mathrm{g} / \mathrm{kg}$, $11.5 \pm 0.63 \mu \mathrm{g} / \mathrm{kg}, 10.16 \pm 0.43 \mu \mathrm{g} / \mathrm{kg}$, and $8.81 \pm 0.33 \mu \mathrm{g} / \mathrm{kg}$, respectively. Similar values were found by Ismail et al. [37]. The obtained results show that the examined minced meat samples had the lowest level of aflatoxins with significant different $(P<0.05)$. The prevalence of aflatoxin residue contamination in meat products may be related to the levels of additives used in processing, the level of additive contamination with aflatoxins, and the levels of aflatoxin residues which might be present in animal muscles. At the same time, the mean values of detected aflatoxins in the examined samples were lower than the permissible limit that has been adopted at $15 \mu \mathrm{g} / \mathrm{kg}$ for aflatoxins [40].

3.1. Public Health Importance. Food safety is a great concern from a public health point of view. While developed countries have established rules and guidelines to observe food quality, and the consumers in these countries expect to find safe food on the supermarket shelves, developing countries are still struggling to put adequate procedures and practices in place. This could be due to lack of guidelines and regulations, or if there are regulations in place, they might not be appropriately enforced. Food safety procedures could also be costly, reducing the producers' already diminishing profit margins. However, the long-term effects of food-borne diseases place an even greater burden on public health, specifically, biogenic amines and aflatoxins, which can cause a variety of diseases including cancer.

Meat and meat products are probably the most frequently consumed food products due to their palatability, nutritional value, low price, and easy preparation methods. Therefore, it is essential that they are safe to consume. Preventing the growth of harmful biogenic amines and aflatoxins is of the utmost importance, as the danger to the wellbeing of consumers presented by contaminated food products is a great worry in many developing countries [17]. Consequently, public health, particularly in developing countries, should concentrate on developing and/or adopting appropriate guidelines and regulations and enforcing them accordingly, regardless of the cost to businesses; otherwise the burden of foodborne diseases will become even higher than anticipated, and the cost will be immense, both in terms of money and people's lives.

\section{Conclusion}

The safety of food is essential and should be made a priority all around the world. As the population of the world is growing steadily, so is the demand for food. This demand especially in developing countries, where food safety guidelines may not be strictly followed, can compromise the safety of food products.

The results of this study suggest that testing meat products for biogenic amines and aflatoxins is a very good indicator of quality and freshness. Although all tested products were found to have various levels of biogenic amines and total aflatoxins, they were all below acceptable levels according to EU regulations regarding the maximum level contaminants in meat and meat products. AFB1 is a potent hepatocarcinogen and was detected higher than the permissible limit in imported luncheon meat and imported hot dog meat samples. Therefore, this study finds that adopting guidelines and/or making it a requirement for all imported meat products to follow these guidelines in their source country could ensure better quality and less harmful products to be on sale in the supermarkets, both from a consumer and public health perspective. When biogenic amines and aflatoxins are at an acceptable level, this reduces the risk of foodborne diseases to the population and therefore it also reduces the burden on public health resources.

\section{Data Availability}

The data used to support the findings of this study are available from the corresponding author upon request. 


\section{Conflicts of Interest}

All authors declare that there are no conflicts of interest.

\section{Acknowledgments}

The Food Control Department, Faculty of Veterinary Medicine, Zagazig University (Egypt) is acknowledged for its support.

\section{Supplementary Materials}

S1: chromatograms of standard curves for eight biogenic amines and two examined samples. S2: chromatograms of standard curves for AFB1, AFB2, AFG1, and AFG2 in ppb using five concentrations. (Supplementary Materials)

\section{References}

[1] M. Gibis, "Heterocyclic aromatic amines in cooked meat products: causes, formation, occurrence, and risk assessment," Comprehensive Reviews in Food Science and Food Safety, vol. 15, no. 2, pp. 269-302, 2016.

[2] V. Patial, R. K. Asrani, and M. Thakur, "Food-borne mycotoxicoses: pathologies and public health impact," in Foodborne Diseases, pp. 239-274, Elsevier, Berlin, Germany, 2018.

[3] J. Stadnik and Z. J Dolatowski, "Biogenic amines in meat and fermented meat products," ACTA Scientiarum Polonorum Technologia Alimentaria, vol. 9, no. 3, pp. 251-263, 2010.

[4] S. Bodmer, C. Imark, and M. Kneubühl, "Biogenic amines in foods: histamine and food processing," Inflammation Research, vol. 48, no. 6, pp. 296-300, 1999.

[5] A. Halász, Á. Baráth, L. Simon-Sarkadi, and W. Holzapfel, "Biogenic amines and their production by microorganisms in food," Trends in Food Science \& Technology, vol. 5, no. 2, pp. 42-49, 1994.

[6] R. Maijala, E. Nurmi, and A. Fischer, "Influence of processing temperature on the formation of biogenic amines in dry sausages," Meat Science, vol. 39, no. 1, pp. 9-22, 1995.

[7] M. A. Alvarez and M. V. Moreno-Arribas, "The problem of biogenic amines in fermented foods and the use of potential biogenic amine-degrading microorganisms as a solution," Trends in Food Science \& Technology, vol. 39, no. 2, pp. 146-155, 2014.

[8] O. Comas-Basté, "Histamine and other biogenic amines in food. From scombroid poisoning to histamine intolerance," in Biogenic Amines, IntechOpen, New York, NY, USA, 2019.

[9] D. M. Linares, B. del Rio, B. Redruello et al., "Comparative analysis of the in vitro cytotoxicity of the dietary biogenic amines tyramine and histamine," Food Chemistry, vol. 197, pp. 658-663, 2016.

[10] B. Del Rio, B. Redruello, D. M. Linares et al., "The dietary biogenic amines tyramine and histamine show synergistic toxicity towards intestinal cells in culture," Food Chemistry, vol. 218, pp. 249-255, 2017.

[11] V. Ladero, M. Fernández, I. Cuesta, and M. A. Alvarez, "Quantitative detection and identification of tyramine-producing enterococci and lactobacilli in cheese by multiplex qPCR," Food Microbiology, vol. 27, no. 7, pp. 933-939, 2010.

[12] M. S. Santos, "Biogenic amines: their importance in foods," International Journal of Food Microbiology, vol. 29, no. 2-3, pp. 213-231, 1996.
[13] F. Gardini, R. Tofalo, N. Belletti et al., "Characterization of yeasts involved in the ripening of Pecorino Crotonese cheese," Food Microbiology, vol. 23, no. 7, pp. 641-648, 2006.

[14] A. Roig-Sagués, A. Molina, and M. Hernández-Herrero, "Histamine and tyramine-forming microorganisms in Spanish traditional cheeses," European Food Research and Technology, vol. 215, no. 2, pp. 96-100, 2002.

[15] G. Suzzi, M. Schirone, M. Martuscelli, M. Gatti, M. Fornasari, and E. Neviani, "Yeasts associated with manteca," FEMS Yeast Research, vol. 3, no. 2, pp. 159-166, 2003.

[16] M.-T. Wyder, H.-P. Bachmann, and Z. Puhan, "Role of selected yeasts in cheese ripening: an evaluation in foil wrapped Raclette cheese," LWT-Food Science and Technology, vol. 32, no. 6, pp. 333-343, 1999.

[17] D. R. Milićević, M. Škrinjar, and T. Baltić, "Real and perceived risks for mycotoxin contamination in foods and feeds: challenges for food safety control," Toxins, vol. 2, no. 4, pp. 572-592, 2010.

[18] J. L. Mietz and E. Karmas, "Chemical quality index of canned tuna as determined by high-pressure liquid chromatography," Journal of Food Science, vol. 42, no. 1, pp. 155-158, 1977.

[19] T. Hernández-Jover, M. Izquierdo-Pulido, M. T. VecianaNogués, and M. C. Vidal-Carou, "Biogenic amine sources in cooked cured shoulder pork," Journal of Agricultural and Food Chemistry, vol. 44, no. 10, pp. 3097-3101, 1996.

[20] S. M. Herzallah, "Determination of aflatoxins in eggs, milk, meat and meat products using HPLC fluorescent and UV detectors," Food Chemistry, vol. 114, no. 3, pp. 1141-1146, 2009.

[21] M. Norussis, Statistical Package for Social Science (SPSS) for Windows Advanced Statistics Release 15.0, SPSS, Chicago, USA, 2006.

[22] C. Ruiz Capillas and A. Moral, "Production of biogenic amines and their potential use as quality control indices for hake (Merluccius merluccius, L.) stored in ice," Journal of Food Science, vol. 66, no. 7, pp. 1030-1032, 2001.

[23] S. Mokhtar, G. Mostafa, R. Taha, and G. S. S. Eldeep, "Effect of different starter cultures on the biogenic amines production as a critical control point in fresh fermented sausages," European Food Research and Technology, vol. 235, no. 3, pp. 527-535, 2012.

[24] R. Maijala and S. Eerola, "Contaminant lactic acid bacteria of dry sausages produce histamine and tyramine," Meat Science, vol. 35, no. 3, pp. 387-395, 1993.

[25] C. Ruiz-Capillas and F. Jimenez-Colmenero, "Biogenic amines in meat and meat products," Critical Reviews in Food Scince and Nutrition, vol. 44, no. 7-8, pp. 489-599, 2005.

[26] A. R. Shalaby, "Separation, identification and estimation of biogenic amines in foods by thin-layer chromatography," Food Chemistry, vol. 49, no. 3, pp. 305-310, 1994.

[27] M. Rekka, "Studies on some chemical substances in some meat products in relation to public health hazard," 2003.

[28] S. Lu, X. Xu, R. Shu et al., "Characterization of biogenic amines and factors influencing their formation in traditional Chinese sausages," Journal of Food Science, vol. 75, no. 6, pp. M366-M372, 2010.

[29] G. Vinci and M. L. Antonelli, "Biogenic amines: quality index of freshness in red and white meat," Food Control, vol. 13, no. 8, pp. 519-524, 2002.

[30] J. Sattler, "Food-induced histaminosis as an epidemiological problem: plasma histamine elevation and haemodynamic alterations after oral histamine administration and blockade of diamine oxidase (DAO)," Agents and Actions, vol. 23, no. 34, pp. 361-365, 1988. 
[31] S. L. Taylor, Histamine Poisoning Associated with Fish, Cheese, and Other Foods, World Health Organization, Geneva, Switerzland, 1985.

[32] T. Hernández-Jover, M. Izquierdo-Pulido, M. T. VecianaNogués, and M. C. Vidal-Carou, "Ion-pair high-performance liquid chromatographic determination of biogenic amines in meat and meat products," Journal of Agricultural and Food Chemistry, vol. 44, no. 9, pp. 2710-2715, 1996.

[33] S. Bover-Cid, M. Hugas, M. Izquierdo-Pulido, and M. C. Vidal-Carou, "Amino acid-decarboxylase activity of bacteria isolated from fermented pork sausages," International Journal of Food Microbiology, vol. 66, no. 3, pp. 185-189, 2001.

[34] A. Önal, "A review: current analytical methods for the determination of biogenic amines in foods," Food Chemistry, vol. 103, no. 4, pp. 1475-1486, 2007.

[35] J. M. Lorenzo, S. Martínez, I. Franco, and J. Carballo, "Biogenic amine content during the manufacture of dry-cured lacón, a Spanish traditional meat product: effect of some additives," Meat Science, vol. 77, no. 2, pp. 287-293, 2007.

[36] IARC, Some Traditional Herbal Medicines, Some Mycotoxins, Naphthalene and Styrene, World Health Organization, Geneva, Switerzland, 2002.

[37] S. Ismail, A. Shehata, and E. El-diasty, "Microbiological quality of some meat products in local markets with special reference to mycotoxins," Journal of Global Veterinaria, vol. 10, no. 5, pp. 577-584, 2013.

[38] C. Regulation, "Setting maximum levels for certain contaminants in foodstuffs," 2006.

[39] R. Garner, "Aflatoxin-a cancer problem that refuses to go away," in Food Safety and Quality Assurance Applications of Immunoassay Systems, M. R. A. Morgan, C. J. Smith, and P. A. Williams, Eds., vol. 93, p. 102, Elsevier Science Publishers Ltd, Berlin, Germany, 1992.

[40] E. Commission, "Commission Regulation (EU) No 594/2012 of 5 July 2012 amending Regulation (EC) 1881/2006 as regards the maximum levels of the contaminants ochratoxin $\mathrm{A}$, non dioxin-like PCBs and melamine in foodstuffs," Official Journal of European Union, vol. 176, pp. 43-45, 2012. 